\title{
The purported Present Perfect Puzzle
}

\author{
Anita Mittwoch
}

\section{Introduction}

The Present Perfect Puzzle (Klein 1992) asks why English sentences in the Present Perfect do not allow a specification of the time of the event. The paper suggests an indirect answer to the question: in languages that do allow this, perfect morphology is ambiguous between a use that is semantically a true Perfect and one that corresponds to a Past (Preterit). A further puzzle in Klein's paper relates to the English Past Perfect: what is wrong with At seven, Chris had left at six? In this case the present paper suggests a direct answer; it attributes the ill-formedness of this sentence to fact that the English Past Perfect is ambiguous.

Klein (1992) raises two questions.

Question I: Why doesn't the English Present Perfect go with temporal adverbials denoting a definite Past interval?

Unlike German, Dutch, Latin, French and many other languages, English does not allow sentences in which definite temporal adverbials modify a sentence in the Present Perfect:

(1) \#She has visited me on Monday / yesterday.

(2) Sie hat mich gestern / am Montag besucht.

\section{Underlying assumptions}

\subsection{Assumptions about the English Perfect}

The Perfect is a composite category; it consists of a state and of an event leading up to the state.

One decisive piece of evidence for the stativeness of the Perfect is compatibility with already and not yet, which occur with lexical statives, with the progressive 
and habituals, both derived statives, and with the Perfect; they do not occur with episodic readings of the simple forms of dynamic verbs.

(3) a. She is already here.

b. She is already leaving.

c. She already goes to school.

d. She has already left.

e. \#She already left. ${ }^{1,2}$

The Tense is determined by a time (usually a point) within the state, which for a present Perfect normally contains utterance time. ${ }^{3}$ I shall call it $\mathrm{P}$ (erfect) E(valuation) Point. PEpt can be expressed overtly by deictic expressions, preferably in initial position, as in (4) or governed by temporal by as in (5):

(4) a. Today I have done my homework.

b. Now I have seen Naples

(5) The guests have left by now

In (4) the time of the event need not be included in the day the sentence is uttered; the utterance can be meant to say today I am prepared.

The meaning of a prepositional phrase consisting of $b y$, followed by temporal expressions like three, Monday, fune, last week is 'not later than the time designated by the referent of the NP' and thus marks the terminal point of an interval during which an event has occurred or will occur; in the first case the $b y$-phrase corresponds to PEpt. The interval is contextually given.

The event component of the Perfect is contained in a contextually determined interval terminating at PEpt. Its beginning can be marked by the preposition since. For a Present Perfect this is McCoard's 'extended now' or XN; but since we need a term that applies to Non-present Perfects as well, I shall call it, following Iatridou

1 For many American speakers, what is said here about already does not apply. They have no problem with (3c) often with reverse order of verb and adverb She LEFT already, and they may also use already with narrow focus: She already left at FIVE. In general, use of the perfect seems to be comparatively rare among such speakers. However, judging by the English of the International Herald Tribune, I believe that formal American English does not differ from British English in this respect.

2 A reviewer notes that the adverb currently is also restricted to states, and asks whether it is good with the present perfect. The following sentence, found on the web, answers the question: 14 teams have currently registered.

3 The only exception is future reference in when-clauses, as in Call me when you have finished. 
et al. (2001), P(erfect) T(ime) S(pan). The beginning of the PTS can be marked by the preposition since. It should be obvious that the temporal $b y$-phrase described in the previous paragraph has a special affinity to the Perfect. ${ }^{4}$

The temporal relations are set out in (6) and shown graphically in (6'):

(6) $\exists i, \exists t, \exists e, \exists s: R B(t, i) \&(e \subset i) \&(e \supset \subset s) \&(i O s)$

where $i$ is the PTS and the PEpt

$\left(6^{\prime}\right)$

i: $\quad \operatorname{xxxxx}|\mathrm{e}| \operatorname{xxxxxxxxxxxx}$

s:

$1 / / / / / / / / / / / / / / / / / / / / / / / / / / / / / / / / / / / / / /$

Following Kamp \& Reyle (1993), (6) says that $e$ abuts $s$, but does not specify the nature of the connection between them, which obviously has to be more than just temporal sequence. I take the state $s$ to be, at its most basic, the post-state of $e$ (Parsons 1990, Vlach 1993), but typically overlaid by an ephemeral state that has some concrete content of its own, depending partly on the use of the Perfect involved, as will be shown below. ${ }^{5}$

\subsection{Assumptions about languages that allow what looks like a straightforward translation equivalent of (1)}

Perfect morphology is ambiguous in such languages; a form like German hat besucht represents either a composite state-event category as in English, or a Past Tense, what Löbner (2002) calls Non-Past Perfect or Past No-Perfect. ${ }^{6}$

In a later paper Klein (2000) supports this position with the examples in (7) and (8):

4 Many existing treatments of the Perfect focus on either the stativeness of the Perfect or on the PTS interval in connection with the event. I believe that both are needed to account for the interaction between the two components of the Perfect. The stativeness determines the properties of the PEpt. The PTS accounts for the occurrence of indefinite temporal adverbials like on a Monday or formerly, and for since-phrases. It also provides a link between the uses of the Perfect discussed in this paper and the Universal Perfect, as in I have lived here for ten years / since 2003.

5 The term post state is due to Klein (1994). Parsons termed it 'resultant state', a state which lasts forever. But as his characterization of this state suggests that it is a property of the referent of the subject, the question arises whether it can outlive that entity. The idea of the post-state is not new. It is clearly enunciated in a classic late nineteenth century work on Ancient Greek: "The perfect, although it implies the performance of the action in Past time, yet states only that it stands completed at the present time." (Goodwin 1889) It may well be much older still.

6 The term 'perfect morphology' stands for an auxiliary corresponding to English HAVE - or BE plus Past participle; it could also correspond to inflected verbs, as in Latin. 
(7) Ich habe im Garten gearbeitet [und muss zuerst einmal duschen]. 'I have in the garden worked [and must-PRES first shower].

(8) Ich habe im Garten gearbeitet [und konnte deshalb die Klingel 'I have in the garden worked [and could-PAST therefore the bell nicht hören].

not hear]

Among additional arguments for this position Löbner mentions temporal als 'when', which is restricted to Past (non-habitual) contexts:

(9) $A l s /{ }^{*}$ Wenn ich sie gestern traf/getroffen habe erzählte sie When I her yesterday met/have met told she mir me $(\mathrm{L} 17 \mathrm{a}, 18 \mathrm{a})^{7}$

Note that if perfect morphology not only in German but in many other languages is ambiguous, one well-known 'peculiarity' of the English Perfect becomes less puzzling. The English Present Perfect exhibits a lifetime effect, like sentences in the Present Tense in general. ${ }^{8}$ Both sentences in (10) are inappropriate when uttered today:
a. Einstein is from Ulm.
b. Einstein has visited Princeton

The German equivalent of (a) is equally inappropriate; but the equivalent of (b) Einstein hat Princeton besucht is unproblematic; its perfect morphology can denote a Past. ${ }^{9}$

The simplest answer to Question I would be: A definite temporal adverbial like yesterday, on Monday refers to a specific time in the past (ignoring on Monday in a future context). Therefore a sentence containing such an adverbial cannot denote simple anteriority, and cannot be absorbed into an Extended Now, the PTS for the Present Perfect. It has to be evaluated at the time specified by the

7 Other scholars arguing for the ambiguity of the German perfect include Fabricius-Hansen (1994), Dahl (1995), Pancheva \& von Stechow (2004).

8 Mittwoch (2008a) argues that lifetime inferences are presuppositional.

9 Klein (2000) treats it as a perfect. He explains the difference between English and German by the claim that in German an operator POST can apply to the predicate alone or to the whole sentence including the subject. English has only the first option, which means that a present property is attributed to the referent of the subject. Since his examples do not appear in a context in which they are unequivocally Perfects, I cannot evaluate this argument. 
adverbial. The presence of such an adverbial in a sentence evaluated at speech time would therefore lead to a clash. The German sentence in (2) is not subject to this restriction because its perfect morphology does not encode a semantic Perfect, and therefore hat besucht in (2) is not a Present Tense form, despite appearances. If this is true for ambiguous 'perfects' in general, then Englishlike languages would not be out of the ordinary; the puzzle would disappear or be replaced by historical questions: why did so many languages allow the state component to fade together with the confinement of the event to anteriority, and why did English and the mainland Scandinavian languages not follow suit? I believe that this is in fact a large part of the answer to Klein's question, but perhaps not a full answer.

This answer has also been challenged by Löbner with what he calls a nonargument for the ambiguity of the German 'Perfect', i.e. perfect morphology in the terminology used here. Löbner, following work by Klein (1992) and Herweg (1990), denies the widely-held assumption that semantic perfect is inherently incompatible with co-occurrence of a specification of event time by means of a definite temporal adverbial:

(11) Jetzt wo Karla gestern hier eingezogen ist, brauchen wir einen

Now where K. yesterday here moved-in is need we a Schlüssel fürs Klo.

key for the loo.

\#'Now that K. has moved in here yesterday we need a key for the toilet.'

(Löbner 2002: (13); I have added the hash)

Since the embedded clause modifies jetzt the italicised verbal phrase must be a semantic perfect. The presence of the adverbial is facilitated, I suggest, by the fact that it is in an embedded clause which does not contain new information, but at most a reminder to which it makes a minimal contribution. One difference between German and English that might also be relevant is the position of the adverb in its clause, and the effect of this on prosody. Gestern, between subject and predicate, requires no prosodic prominence; the English equivalent has the adverb in clause-final position immediately before resumption of the matrix, and would require a slight rise. ${ }^{10}$

${ }^{10}$ One of my informants rejected an analogous sentence (fetzt wo ich den Film gestern gesehen habe kann ich ihn dir sehr empfehlen) because of the presence of gestern, but did not know why. Others were happy with it. Since I thought that the presence of the adverb was also facilitated by its position in a place where it does not require prosodic prominence, I tried the sentence with the 
If Löbner's claim reflects a robust German phenomenon, then semantic perfect in German is obviously very different from Perfect in English and English-like languages. In the next section I will show why the relevant temporal adverbial are incompatible with two of the main uses of he English Perfect.

\section{How would temporal adverbials affect Resultative and Experiential Perfects?}

Descriptions of the English Perfect usually distinguish a number of 'uses'. In what follows I shall discuss two of these, the Resultative and the Experiential Perfect, and show that for each of them there is a different factor at work that blocks co-ocurrence with definite temporal adverbials. Before presenting examples I must make it clear that the distinction is between uses of sentences rather than meanings; many sentences in isolation could belong to either category. A hash in the examples below is to be read as 'unacceptable as a Resultative Perfect'. This will be explained more fully and exemplified at the end of this section.

\subsection{The Resultative}

The Resultative is the oldest and still the prototypical use of the Perfect. It involves an episodic event and a clearly defined result state. In what I have called Strong Resultatives the result state is the target state of a telic event, and can be read off the event sentence (Mittwoch 2008b). The target state of the untensed VP lock the door is the door be locked. From an utterance of (12a) one can normally infer (12b):
a. Fill has locked the door.
b. The door is now locked.

If the speaker has reason to suspect that someone else has meanwhile unlocked the door again, the Perfect is inappropriate; the Past Tense is called for: \#fill has locked the door, but I am not sure whether it is still locked. For Weak Resultatives the nature of the result state is not dictated by the meaning of the verb, but has to be inferred from the extra-linguistic context: for example, from an utterance of I've had lunch, the hearer may infer that the speaker is not going to have lunch right now, or simply that s/he is not hungry.

addition of schon before the adverb, which would then require focal stress. Two informants were not bothered, one would have preferred schon before eingezogen. 
For the Resultative Perfect the definite temporal adverbial is only one of a series of constituents that is excluded. Thus
a. Jane has translated the poem \#quickly/literally.
b. They have sealed the door \#noisily/hermetically.
c. I've had lunch \#in the cafeteria/\#with Anne.

Any adverbial that modifies only the event VP is out. For the Strong Resultatives in (13a and b) the acceptable adverbials literally and hermetically modify the target state, witness a literally translated version of the text, a hermetically sealed door. ${ }^{11}$ Even the subject position of change of state verbs is affected, inasmuch as it cannot be the focus of a question or a cleft sentence, unless it is relevant to the target state:
a. Who has \#broken/ taken my umbrella?
b. It's John who has \#broken /taken your umbrella.

A broken umbrella is not expected to show signs of the culprit; but there is a good chance that the person who has taken my umbrella has it now.

The Resultative Perfect is state-oriented. A definite temporal adverbial has to be excluded from this Perfect because it would modify only the event.

\subsection{The Experiential Perfect}

In contrast to the Resultative, the event component of an Experiential Perfect is non-specific. A sentence in this type of Perfect merely says that an event type is instantiated in the PTS. The state component may be no more than the 'poststate'; or it may allow inferences based on world knowledge, what is called the 'present relevance' of the Present Perfect.

Many examples of such Perfects explicitly refer to a plurality of events by means of adverbs of quantity like sometimes, three times, etc.

(15) We have often dined in that restaurant with guests.

In other cases it is left vague whether a single event is involved or a multiplicity of instantiations. The beginning of the PTS may be marked by the preposition since:

(16) Since graduating, she has (already) been back in Cambridge twice.

\footnotetext{
${ }^{11}$ According to two informants the facts are the same in Swedish.
} 
The post-state being somewhat nebulous, the Experiential Perfect gives the impression of being event-oriented. But as the event component is purely quantificational, a definite temporal adverbial is incompatible with an Experiential Perfect as we know it, because by its nature such an adverbial would individualize the event and make it specific.

\subsection{The relationship between Resultative and Experiential}

Semantically, this relationship is asymmetrical. Although the Resultative is more basic and perhaps more common, Resultative one-sidedly entails Experiential. If there is a specific token of an event type, the type is obviously instantiated. (McCawley 1981, Mittwoch 2008b). Sentences that out of the blue are likely to be interpreted as Resultative can in suitable contexts be interpreted as Experientials, but the reverse is not true. For example, if you see a policeman approaching, and say to the person sitting next to you in the car

(17) (Oh dear!) I've left my driving license at home.

the Perfect is likely to be a meant as a Resultative. But if you complain to your doctor that you have been unusually absent-minded lately and say

(18) I've forgotten to lock the front door, I've left my driving license athome, I've taken the wrong turning on my way to work.

all three Perfects are Experiential; at utterance time the door need not be open, the speaker is not driving, and the license may be in his pocket. On the other hand, (15) and (16) above cannot be used as resultatives.

\section{The Past Perfect and Klein's second question}

In the Past Perfect a temporal adverbial can refer either to the PEpt or to the time in which the event occurred, a notorious problem for Reichenbach's analysis of 'the tenses of verbs' (Reichenbach 1947:290), in particular his R(eference time). (19) is ambiguous (as printed) between these readings, as shown when it is placed in contexts in (20a and b):

(19) Chris had left at six.

(20) a. Mary came home at six. Unfortunately Chris had already left at six.

b. Yesterday, Mary came to Chris's office at seven. But Chris had left at six. (Klein 1992: 40) 
In terms of information structure these sentences are very different. In (20a) six is old information, left is new and carries focal stress; in (20b) left at six is new, and focal stress is on six. Consider also

(21) John had left the house when I arrived.

On the reading corresponding to (20a) John was no longer in the house at the time of my arrival. On the reading corresponding to (20b) the event of John's leaving is likely to have occurred a short time - perhaps only a minute - after the event of my arrival. (This is not a necessary inference, however; if my arrival would serve as a signal for John's leaving, and if he saw me coming from a distance, the two events could be simultaneous.)

Question II: Why can't two temporal adverbials occur together in one clause, with one marking the evaluation time and the other the event time, as in (22)?

$$
\text { \#At seven, Chris had left at six. (Klein 1992: (41) and (44)) }
$$

Klein's answer to Question II: The reason is neither syntactic nor semantic. (22) is true if $(20 \mathrm{~b})$ is true. The reason is pragmatic: "it gives the somewhat unfortunate impression that at some other time yesterday Chris had not left at six." ${ }^{12}$ This leads him to postulate the constraint in (23):

POSITION (p) - definiteness constraint:

In an utterance, the expression of TT Topic Time $=($ Evaluation

Time) and the expression of TSit (Situation Time= Event Time) cannot both be independently p-definite. (Klein 1992: (43))

He points out that this constraint also covers the ban on definite temporal adverbials in the Present Perfect, since utterance time is also a 'topic time'.

Klein's answer to the question he has posed, and the constraint based on it are correct. But there is also solid semantic evidence for the ill-formedness of (22).

In spite of pointing out the two different temporal positions to which the adverbial can belong, Klein assumed that the perfect morphology in (20a and b) has the same function. ${ }^{13}$ The examples below, from Mittwoch (1995), show that there are 'Past Perfects' that are incompatible with definite temporal adverbials:

${ }^{12}$ In the paper's concluding remarks Klein says that "the solution to the present perfect puzzle has a semantic component - the meaning of the English perfect construction - and a pragmatic component"; but the paper does not make it clear how the semantic component operates.

13 The assumption is shared by many recent discussions of the English Perfect, (Katz 2003, Portner 2003, Reyle et al. 2007, Schaden 2009). On the other hand, Kamp \& Reyle (1993) and Kiparsky (2002) discuss the ambiguity at length. Kiparsky, who, contrary to the position taken here, believes that the difference between Experiential and Resultative is truth-conditional, relates the PPerf reading to the former and the Resultative reading to the latter. 
a. I phoned at 7, but Mary had \#already left at six that morning.

b. Since leaving Cambridge, Mary had been back \#last summer.

Already in (24a) and since in (24b) are markers of semantic Perfect. The trouble with both sentences is exactly the same as the trouble with present Tense sentences like (1): She has visited me on Monday / yesterday. Past perfect morphology in English can correspond to a Past of a Perfect or to an iterated Past. In Mittwoch (1995) these are called PPerf and PPast respectively.

The two uses cannot be mixed in one sentence. Klein's own example in (22) is in fact another case of such illegitimate mixing.

Neither can they be conjoined with ellipsis of the auxiliary:

a. John had already arrived, and \#(had) gone to the dining room at seven.

b. John had arrived at seven and \#(had) already gone to the dining room.

In coordinations where Past Tense morphology stands for the same type the auxiliary can be omitted:

a. Mary had already finished her degree and started work.

b. Mary had finished her degree and started work last October.

These examples provide clear evidence that the auxiliaries have different functions in the two conjuncts in (25a and b).

In the following example the PPast reading is recognized not only by the temporal adverbial in the introductory sentence, but also by its containing a narrative sequence, which would be incompatible with a true Perfect (cf. Kamp \& Reyle 1993: 594 and Michaelis 1994, who makes this point about the Present Perfect):

(27) (fohn had come in at five.) He had switched on the TV, opened a can of beer and settled down in his armchair.

Apart from the adverbs already and not yet, temporal by is a sure diagnostic for a PPerf. It is probably commoner than the prepositions at, in, on to mark PEpt in PPerf:

(28) The workers had finished the job by 4/ Friday afternoon/ June.

Past perfect morphology in English displays basically the same ambiguity as present perfect morphology in German, Latin and many other languages. Perfect morphology can represent a true Perfect or function as a stand-in for Past, in this 
case the 'Inner' Past in the scope of the Past operator that is spelled out in the case of have as had.

The two readings of (19) given in (20a and b) are shown in (29):
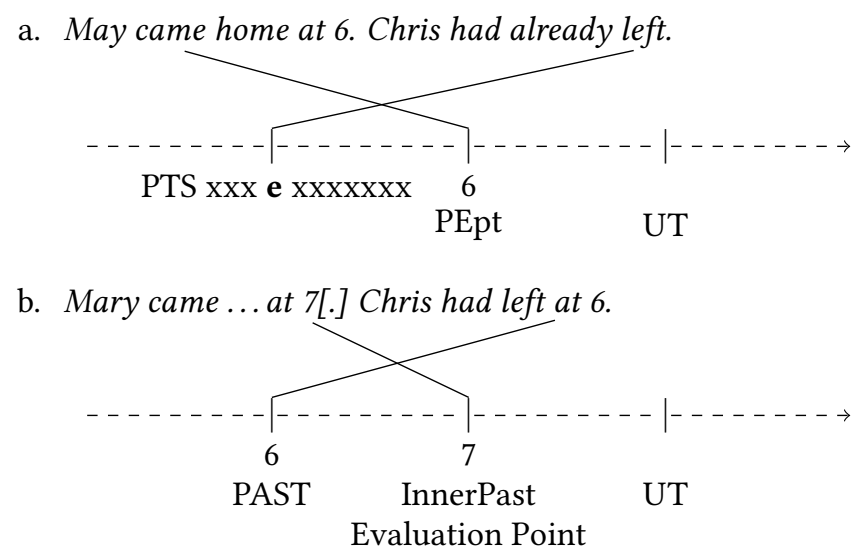

There is one apparent difference between the Past Perfect in its PPerf function and the Present Perfect. Several authors who regard only the Present Perfect as puzzling support this position by denying that the Past Perfect exhibits a lifetime effect, citing the well-formed sentence

(30) Einstein had visited Princeton.

Needless to say, (30) is not a counterexample to the position adopted here since its perfect morphology can denote a PPast. For a lifetime effect we would need a clear PPerf sentence, with PEpt later than Einstein's death. Suppose a famous Russian scientist, after escaping from the Soviet Union, visited Princeton or some other famous Western university in 1960. Suppose further that we had just heard about this event, and we knew that Einstein died in 1955. Would we react to (31) as to the corresponding Present Perfect sentence?

(31) Einstein has already visited Princeton. (=(10b))

It sounds pretty unlikely, quite apart from the fact that the function of already is unclear. Or, supposing that we knew that Columbus died in 1506, would we be disturbed by (32)?

(32) In 1510 when the Portuguese conquered Goa, Columbus had already discovered America. 
I find it only slightly more likely that there would be a lifetime effect. I suspect that the explanation for the absence of such an effect in the Past Perfect is that historical knowledge does not have the same impact as knowledge about wellknown figures in our own temporal environment.

\section{Other Non-Present Perfects}

The ambiguity of the Past Perfect is paralled in all non-present perfects. On one reading they are true Perfects, with a PEpt in the Past or future (or Present in infinitivals). On the other reading they denote an Inner Past relative to a Past a modal or an infinitive.

(33) illustrates a mixed perfect morphology to-infinitive, (35) an illegitimate conjunction of bare infinitives governed by an epistemic modal, and (34) a similar mixture involving future will:

(33) We seem to have already found a suitable candidate \#yesterday. ${ }^{14}$

(34) Fohn may have changed his mind since then, and \#(have) spoken to the Dean yesterday. ${ }^{15}$

(35) Anne will arrive the day after tomorrow. Everybody else will have already arrived \#yesterday, today or tomorrow.

\section{Concluding remarks}

I have argued that the temporal adverbial in (1) \#I have visited her yesterday is in conflict with the Present Tense of the sentence. The Tense that such an adverbial is related to can only be a Past. In a Perfect of Result such a temporal adverbial would also share the constraint barring other adverbials that do not modify the result state. In an Experiential Perfect they would impose a specific singular interpretation of the event. Non-Present Perfects in English are ambiguous in the same way as Present Perfects in German and many other languages. I have given examples showing that the two readings of sentences in Non-Present Perfects cannot be mixed in one clause. This applies in formal English; for many speakers, especially American speakers, the line dividing these readings may well

${ }^{14}$ The ambiguity of infinitives with perfect morphology was pointed out by Hofmann (1976)

${ }^{15}$ This example sounds better to my ear with repetition of may as well as have. 
be blurred, or they may not have Non-Present Perfects at all. I suspect that the same is true for speakers of German with regard to the Present Perfect.

\section{Bibliography}

Dahl, Ö. 1995. The tense system of Swedish. In Tense systems in European languages, vol. II, Tübingen: Niemeyer.

Fabricius-Hansen, C. 1994. Das norwegische und dänische Tempussystem im Vergleich mit dem deutschen. In R. Thieroff \& J. Ballweg (eds.), Tense systems in European languages, Tübingen: Niemyer.

Goodwin, W. W. 1889. Syntax of the moods and tenses of the Greek verb. London: Macmillan.

Herweg, Michael. 1990. Zeitaspekte. Die Bedeutung von Tempus, Aspekt und temporalen Konjunktionen. Wiesbaden: Deutscher Universitätsverlag.

Hofmann, T. 1976. Past tense replacement and the modal system. In J. D. McCawley (ed.), Syntax and semantics 7: Notes from the linguistic underground, 86-100. New York: Academic Press.

Iatridou, S., E. Anagnostopolou \& R. Izvorski. 2001. Observations about the form and meaning of the perfect. In M. Kenstowicz (ed.), Ken Hale: A life in language, chap. 6. Cambridge, Mass.: MIT Press.

Kamp, H. \& U. Reyle. 1993. From discourse to logic. Dordrecht: Kluwer.

Katz, G. 2003. A modal account of the present perfect puzzle. In R. Young and Y. Zhou (eds), SALT XIII, 145-161, Ithaca, NY: Cornell University.

Kiparsky, P. 2002. Event structure and the perfect. In Beaver D. I., L. D. C. Martinez, B. Z. Clark \& S. Kaufmann (eds.), The construction of meaning, CSLI publications.

Klein, W. 1992. The present perfect puzzle. Language 68. 525-552.

Klein, W. 1994. Time in language. London: Routledge.

Klein, W. 2000. An analysis of the German perfect. Language 76. 358-382.

Löbner, S. 2002. Is the German perfect a perfect perfect. In I. Kaufmann \& B. Stiebels (eds.), More than words: A festschrift for Dieter Wunderlich, 369-391. Berlin: Akademie Verlag.

McCawley, J. 1981. Notes on the English present perfect. Australian fournal of Linguistics 1. 81-90.

Michaelis, L. 1994. The English present perfect. Fournal of Linguistics 30. 111-158. Mittwoch, A. 1995. The English perfect, past perfect and future perfect in a neoreichenbachian framework. In P. M. Bertinetto, V. Bianchi \& Ö. Dahl (eds.), 
Temporal reference, aspect and actionality: Typological perspectives, vol. 2, 255267. Torino: Rosenberg and Sellier.

Mittwoch, A. 2008a. Tenses for the living and the dead: Lifetime inferences reconsidered. In S. Rothstein (ed.), Theoretical and crosslinguistic approaches to the semantics of aspect, Amsterdam: Benjamins.

Mittwoch, A. 2008b. The English resultative perfect and its relationship to the experiental perfect and the simple past tense. Linguistics and Philosophy 31. 323-351.

Pancheva, R. \& A. von Stechow. 2004. On the present perfect puzzle. In K. Meulten \& M. Wolf (eds.), Proceedings of NELS 34, .

Parsons, T. 1990. Events in the semantics of English. a study in subatomic semantics. Cambridge/Mass.: MIT Press.

Portner, P. 2003. The (temporal) semantics and (modal) pragmatics of the perfect. Linguistics and Philosophy 26. 459-510. Issue 4.

Reichenbach, H. 1947. Elements of symbolic logic. London: Collier-Macmillan.

Reyle, U., A. Rossdeutscher \& H. Kamp. 2007. Ups and downs in the theory of temporal reference. Linguistics and Philosophy 34. 565-635. Issue 5.

Schaden, G. 2009. Present perfects compete. Linguistics and Philosophy 32 (2). 115-141.

Vlach, F. 1993. Temporal adverbials, tenses and the perfect. Linguistics and Philosophy 16. 231-283.

\section{Author}

Anita Mittwoch

English Department

The Hebrew University of Jerusalem

anita.mittwoch@mail.huji.ac.il 